\title{
Availability of Community-Based Mentoring Program for Children and Youth: A Case of Karachi-Based Communities
}

\author{
Anila Nazish* \\ Wajeeha Zameer** \\ Kiran Hashmi****
}

\begin{abstract}
This study aimed to explore the availability of community-based mentoring programs for children and youth within the various communities including Bohri, Ismaili, Memon, Parsi, Christian, and Hindu in Karachi, Pakistan. It also aimed to understand the impact of community and community-based mentoring programs on children and youth's overall development to analyse the gaps in existing mentoring programs implemented by the communities. Using a qualitative research study approach, the data was gathered using a predesigned interview guide from the individuals who belonged to the chosen communities. The findings of the study revealed a severe lack of recognition and a lack of community-based mentoring programs among the targeted communities of Karachi. Furthermore, it was found that children and young adults were not satisfied with their careers and educational choices due to various external and internal factors and intensely desired guidance. It recommends the communities initiate community-based social, emotional and professional development and mentoring programs for children and youth.
\end{abstract}

Keywords: children development, community-based programs, Karachi-based communities, mentoring programs, youth development

\footnotetext{
* Faculty of Humanities and Social Sciences, Hamdard University. email: anila.edu2019@gmail.com

** Faculty of Humanities and Social Sciences, Hamdard University. email: wajeehazameer004@ gmail.com

*** College of Education, Ziauddin University. email: kiran.hashmi@zu.edu.pk
} 


\section{INTRODUCTION}

The term community is used in the context of the same religion, language, ethnicity, cultural values, and norms. It speaks of a cohesive body of individuals, such as people with common features or interests living together within a larger society ${ }^{1}$. As human beings are said to be social beings, a community without any question is central for every individual, providing a sense of belonging and connection to everyone living within society. When it comes to children and youth, it is essential to highlight the importance of community, contributing significantly to their socio-emotional and professional development. The terms children and youth are used for two different sets of individuals. Children are the individuals who fall in the age group of 1 to14, whereas youth are referred to as individuals between 15 to 24 years $^{2}$.

The involvement of the community in children and youth's overall development empowers them to feel safe, accepted, and valued from social, emotional, mental, and physical aspects. They can develop certain social skills and abilities and empathy for each other. Deprived of being a part of a community, a child may feel isolated, without help, confused, and does not have the right direction for the future ${ }^{3}$. These individuals tend to cultivate a feeling of worthlessness and are starved of love, affection, and support, which are the core components of growth and development. Hence, for children and youth to feel treasured, uplifted, encouraged, and directed in the right path, community-based mentoring is the most important element that must be added in all communities to better the future generation ${ }^{4}$. Mentoring can be delineated as a bridge to connect people to aid certain proficiencies, skills, or pathways to lead fulfilling lives. The purpose of community-based mentoring is not merely guidance or counselling for a certain period or a specific aspect of life; instead, it focuses on holistic development, which takes account of the cultivation of social, emotional, and cultural intelligence in children and youth from a very young age.

Such programs allow youngsters to identify their strengths, weaknesses, determine their interests, and achieve a prominent position in society ${ }^{5}$. It is not only focused on financial support, but on enlightening children in such a way that transmutes them into civilized members of the social order. Several studies have revealed ample benefits of community-based mentoring programs for children and young adults, whether the mentorship transpires naturally or through some predesigned programs. Bridgeland and Moore opine that natural mentoring, which arises instinctively in the form of the teacher-student relationship, between a coach or an athlete, an

\footnotetext{
${ }^{1}$ Pahwa, Rohini, Melissa E. Smith, Erin L. Kelly, Ryan J. Dougherty, Helle Thorning, John S. Brekke, and Alison Hamilton. "Definitions of community for individuals with serious mental illnesses: Implications for community integration and recovery." Administration and Policy in Mental Health and Mental Health Services Research 48 (2021): 143-154.

2 Eccles, Jacquelynne S. "The development of children ages 6 to 14." The future of children (1999): 30-44.

${ }^{3}$ Heywood, Jean S. Children in care: the development of the service for the deprived child. Routledge, 2013.

${ }^{4}$ DuBois, David L., and Thomas E. Keller. "Investigation of the integration of supports for youth thriving into a community-based mentoring program." Child Development 88, no. 5 (2017): 1480-1491.

5 Axford, Nick, Gretchen Bjornstad, Justin Matthews, Laura Whybra, Vashti Berry, Obioha C. Ukoumunne, Tim Hobbs et al. "The effectiveness of a community-based mentoring program for children aged 5-11 years: Results from a randomized controlled trial." Prevention Science 22, no. 1 (2021): 100-112.
} 
experienced friend, or any other non-parental adult, have resulted positively in several dimensions ${ }^{6}$, which include:

- Education and Profession: Prevention of dropout rate, completion of high school, college, and cultivation of better future ambition

- Physical Health: Creating discipline as well as a balanced lifestyle among youth, incorporating exercise

- Mental Health: Informed decision making, improved self-esteem

- Behavioural Issues: Prevention of substance abuse, gang involvement, or any form of harmful activities

In addition to this, community-based mentorship has exhibited noticeable benefits for mentees and mentors as well. It influences the academics and personal life paths of children and adolescents. Some benefits for children and young adults include (a) personalized goal setting, which allows youth to evaluate their progress and cultivate general skills essential for success in life, academics, and career. These skills include setting achievable goals, adaptability, and reflection; (b) building relationships of trust to instils social intelligence in children and youth, which they develop while fostering relationships with their mentors; and (c) self-awareness and ambition for the future; identifying the personal interest, strengths and weaknesses to inculcate self-awareness among children and youth. Benefits for mentors include inclusion and impactful experience, which allows mentors to influence all their mentees by getting to know them personally. Hence, these mentors strive to enlighten themselves to make an impact on mentees ${ }^{7}$.

Profuse research studies and case studies have been conducted in this field internationally that have highlighted the substantial role played by community-based mentoring programs in the upbringing of children and youth ${ }^{8,9, \& 10 .}$ Many mentoring programs are found globally, including Big Brothers Big Sisters of America (BBBSA) ${ }^{11}$. It is one of the most conspicuous mentoring programs and consists of more than 500 agencies throughout the USA. Furthermore, United Way of America, in collaboration with One to One Organization, has contributed noteworthy advancement in mentoring initiatives at local, state, and national levels in the USA. These oneon-one procedures consist of relevant information, material, and curriculum for mentorship required to establish mentoring programs ${ }^{12}$. Similarly, the UK, Ireland, Canada, Australia, Africa, and many other countries have also received subsidies from mentoring programs and

6 Bridgeland, John M., and Laura A. Moore. "Untapped Potential: Fulfilling the Promise of Big Brothers Big Sisters and the Bigs and Littles They Represent." Civic Enterprises (2010).

7 Summit Learning, "Power Of Mentorship: Why Every Student (And Teacher) Benefits", Summit Learning Blog, Last modified 2019, https://blog.summitlearning.org/2019/01/mentorship-benefits/.

8 Herrera, Carla, Cynthia L. Sipe, and Wendy S. McClanahan. "Mentoring school-age children: Relationship development in community-based and school-based programs." (2000).

9 Guillen, Lorena, and Ken Zeichner. "A university-community partnership in teacher education from the perspectives of community-based teacher educators." Journal of Teacher Education 69, no. 2 (2018): 140-153.

10 Ruiz-Casares, Mónica, Lauren Kolyn, Richard Sullivan, and Cécile Rousseau. "Parenting adolescents from ethnocultural backgrounds: A scan of community-based programs in Canada for the promotion of adolescent mental health." Children and Youth Services Review 53 (2015): 10-16.

11 Beiswinger, George L. One to one: The story of the Big Brothers/Big Sisters movement in America. Philadelphia: Big Brothers/Big Sisters of America, 1985.

12 Johnson, Amy W., and Judith A. Sullivan. "Mentoring program practices and effectiveness." New Directions for Adult and Continuing Education 1995, no. 66 (1995): 43-56. 
have launched many programs to support the children and youth of their countries for more than a decade now. However, when the focus is shifted from international to Pakistan, a severe lack of awareness and knowledge about mentoring programs is observed in Karachi, a cosmopolitan city of Pakistan. Even if a few communities have been following or practising programs of some kind, they have unfortunately not been made known to other communities, who could also benefit and serve the nation.

\section{Purpose of the study}

This study aims to explore the availability of community-based mentoring programs for children and youth within the various communities including Bohri, Ismaili, Memon, Parsi, Christian, and Hindu in Karachi, Pakistan. As far as the professional journey is concerned, it has been witnessed that low self-esteem, low self-efficacy, poor decision-making skills, and poor career choices are shared among most children and youth in Karachi. Whether the children are taught in a class setting, individually, or in remedial classes, they are detected to lack direction or ambition that spark the motivation to learn and strive through life successfully. It seems like a vicious cycle where there is no direction and no incentive to get better in life. As a result, it has become a dire need to establish community-based mentoring programs among different communities to support the country's future generation as a whole. To date, a few communities have taken the initiative to overcome these challenges and have been reasonably successful in reducing the shortage within their communities. Nonetheless, there is still no evidence of formal communitybased mentoring programs found within these communities, which could impact the future generation holistically. Thus, a well-organized Community-Based Mentoring Program (CBMP), which can reduce or prevent these challenges, needs to be introduced in Karachi.

The objectives of this research study are three-fold:

- To understand the impact of community and community-based mentoring programs for children and youth's overall development

- To investigate the availability of community-based mentoring programs in Karachi

- To analyse the gaps in existing mentoring programs implemented by the communities

\section{LITERATURE REVIEW}

Issues such as low self-esteem, inadequate decision-making skills, and poor career choices have been observed unceasingly during my career as an educator. The majority of the children and youth of Karachi seem to be unaware of the prominence of education, appropriate decisionmaking, and which career choice is best for their future according to their strengths, weaknesses, and interests. Most of them depend on and follow what they are merely told by their parents, peers, or society, instead of self-evaluating or analysing what they truly desire to achieve in life. The embedded question that persuaded this study was why only a few communities can moderately succeed in life and why not the nation.

\section{Self-esteem}

The word self-esteem refers to a person's sense of self-worth.; hence, the need for self-esteem is a central human drive that stimulates a person to make better personal and professional decisions 
throughout life ${ }^{13}$. It is critical for children and youth to develop proper self-esteem to move throughout their lives competently. Thus, in the light of Maslow's self-actualization theory, it is noticeable that self-esteem is the fourth level of the hierarchy of needs and the need for achievement, competence, independence, and respect. Accordingly, all human beings desire to experience good social status, reputation, and respect from others. Children and youth require care and importance the most during their journey towards adulthood, thus shaping their personality and life direction ${ }^{14}$.

The detailed study of this phenomenon from multiple dimensions of psychology, for example, clinical counselling and developmental psychology have shown self-esteem as paramount for many behavioural effects. It is the pre-eminent factor for the emotional health of a person. Thus, people with high self-esteem are self-aware and emotionally stable, as observed by Fanaj and Melonashi ${ }^{15}$. Low self-esteem is said to be interrelated with other factors, for instance, low selfesteem and depression, which ultimately lead to poor or vague personal and professional decisions $^{16}$. Low self-esteem and depression are not necessarily interlinked; rather, it indicates low self-esteem as a symptom of depression. Academic and professional success may boost selfesteem; however, it is not the other way as there are no laboratory studies that could prove these assumptions $^{17}$.

Likewise, various studies have revealed the effects of low self-esteem. Children or young adults who are depressed tend to encounter low self-esteem and vice versa; therefore, they are at higher risk to be involved in crimes and possess poor physical, emotional, and mental health ${ }^{18}$. There are high probabilities of emotional and behavioural disorders such as anxiety, panic attacks, melancholy, and absence of motivation associated with low self-esteem. Behavioural conditions such as suicidal inclinations, criminal behaviour, and eating disorders are also witnessed among individuals with low self-esteem ${ }^{19}$. These individuals often feel indecisive, stressed, and implicate in self-pity because of their overall idea of self-worthiness. Contrary to this, positive self-esteem magnifies positive emotions, proactivity, and motivation ${ }^{20}$.

\footnotetext{
${ }^{13}$ Li, Jiwen, Mingyan Liu, Maoying Peng, Ke Jiang, Hong Chen, and Juan Yang. "Positive representation of relational self-esteem versus personal self-esteem in Chinese with interdependent selfconstrual." Neuropsychologia 134 (2019): 107195.

${ }^{14}$ McLeod, Saul. "Maslow's hierarchy of needs." Simply psychology 1, no. 1-18 (2007).

${ }^{15}$ Fanaj, Naim, and Erika Melonashi. "A systematic literature review on self-esteem and psychological well-being in Kosovo." In Human and Social Sciences at the Common Conference, pp. 103-108. 2014.

${ }^{16}$ Baumeister, Roy F., Jennifer D. Campbell, Joachim I. Krueger, and Kathleen D. Vohs. "Does high self-esteem cause better performance, interpersonal success, happiness, or healthier lifestyles?." Psychological science in the public interest 4, no. 1 (2003): 1-44.

${ }^{17}$ Baumeister, Roy F., Jennifer D. Campbell, Joachim I. Krueger, and Kathleen D. Vohs. "Does high self-esteem cause better performance, interpersonal success, happiness, or healthier lifestyles?." Psychological science in the public interest 4, no. 1 (2003): 1-44.

${ }^{18}$ Fanaj, Naim, and Erika Melonashi. "A systematic literature review on self-esteem and psychological well-being in Kosovo." In Human and Social Sciences at the Common Conference, pp. 103-108. 2014.

${ }^{19}$ Feldman, S. Shirley, Glen R. Elliott, and Glen R. Elliott, eds. At the threshold: The developing adolescent. Harvard University Press, 1990.

20 ibid.
} 


\section{Mentorship}

A case study of The Healthy Kids Mentoring Program conducted by King, Vidourek, Davis, and McClellan validated that mentorship helped to enhance self-esteem among fourth-grade children at Midwestern Suburban Public School USA, who were identified with low self-esteem ${ }^{21}$. The result of the program indicated that mentored children's overall self-esteem and connectedness towards school, family, and friends were considerably high at the time of the post-test than at pre-test time. In addition, according to the theory of self-psychology, the results of social connectedness are twofold ${ }^{22}$.

- Children expand their self-esteem, social skills, and self-management when they persistently obtain empathy, praise, and attention from idealized others (mentors). It allows them to feel more encouraged and linked with their parents, friends, and teachers.

- Advancement in self-esteem, social skills, and self-management also prove to assist connectedness towards academics and activities involved within the context, such as reading and writing.

On the other hand, this advancement process often occurs within the milieu of dyadic relationships, e.g., parents, teachers, peers, or mentors. Time and again, mentoring programs have proved to have a noteworthy stimulus on children, adolescents, and adults in the direction of positivity and development. As a result, mentoring programs help in academics, profession, and cultivate a skill set and assist in shaping the holistic character of children. To illuminate that mentoring programs help not only children and youth but also adults, Holland conducted a study with male African American adolescents and found that 100 per cent of mentees benefited from the mentoring program ${ }^{23}$. Moreover, mentors in this case study accomplished the need for a father figure in the mentees' lives that profoundly intensified their confidence and motivation to pursue professional growth and development.

\section{Community-Based Mentoring Program}

The community-based mentoring program is one of the oldest forms of mentoring models, which later modified into school-based and employer-based mentoring programs. There are other forms of community-based mentoring programs, such as one-on-one mentoring, which means one adult [mentor] and one young person [mentee]; adult to youth ratio in which a few mentors work with a small group of young mentees; group mentoring, in which there is one older mentor with four mentees; E-mentoring or distance mentoring, where mentoring transpires utilizing the internet and peer mentoring in which mentoring incorporates one-on-one mentoring between people who are in the same profession, developmental stage or age group. The core focus of this program model is to emphasize mentor-mentee relationships by appointing them more to social activities

${ }^{21}$ King, Keith A., Rebecca A. Vidourek, Beth Davis, and Warren McClellan. "Increasing self-esteem and school connectedness through a multidimensional mentoring program." Journal of school health 72, no. 7 (2002): 294299.

${ }^{22}$ Flanagan, Laura Melano. "The theory of self psychology." Inside out and outside in: Psychodynamic clinical theory and psychopathology in contemporary multicultural contexts 4 (2011): 158-185.

${ }^{23}$ Holland III, Melvin A. "Youth Mentoring Through Otherfathering: A Case Study Exploring Adolescent African American Males' Mentor-Mentee Relationship Experiences with African American Men Acting as Otherfathers in an Urban Community-Based Mentoring Setting." PhD diss., Northeastern University, 2019. 
instead of academic activities. Discussion of personal concerns is one of the significant components of social movements. Mentors in this type of model tend to interact with mentees' parents and siblings, enabling them to impact mentees' social skills, self-esteem, and relationships with family members and successfully develop empathy.

Additionally, mentor-mentee matches are the same gender in community-based mentoring programs, which is beneficial for mentees to experience connectedness. These mentor-mentee matches meet at mutually pre-decided sites for two to three hours a week for an entire year to accomplish the positive results of the journey. The profound aspect of this model is the mentors' screening process, which is said to be time taking and more rigorous as compared to other models ${ }^{24}$. The screening process demonstrates the severity of the program model and the mentors. They want to voluntarily and purposefully guide the young adults in the right direction and enlighten them with the help of their personal life experiences. The community-based mentoring program is a far-reaching model, which in addition to academic success, also focuses on the social, emotional, and professional development of mentees. The community-based program aims to lessen the risk factors of negative behaviours that children and youth might get involved in and increase the protective factors of positive behaviours.

Benefits of Community-Based Mentoring Programs

Various research studies were piloted to analyse the impact of community-based mentoring programs. For instance, a meta-analytical review of 55 evaluations of mentoring programs conducted by DuBois discovered practical benefits of the community-based mentoring program in diverse areas like academics, social skills, behavioural issues, and career outcomes, although these benefits were modest yet had profound effects on youth's overall development ${ }^{25}$. Rhodes also reinforces the favourable outcomes of the community-based mentoring programs ${ }^{26}$. Children and youth who participated in the community-based mentoring program had better physical and social health than those who did not opt for any mentoring program. The positive results of community-based mentoring programs on youth's social and emotional health, which are subject to risk. The most common dynamics that highlight community-based mentoring programs as more effective are meeting hours for two to three hours a week for an entire year and the emphasis on community-based mentoring programs to develop quality relationships.

Social media sites like Instagram, Facebook, and Snapchat conveniently grant access to content exposing celebrities and influencers engaging in substance use, hence normalizing the trends of being high ${ }^{27}$. What persists as the primary concern about community-based programs is that prolonging mentor-mentee matching. It may cause a decline in the mentee's mental health which already requires help. Mentees and parents may feel discouraged and opt for the program before

\footnotetext{
${ }^{24}$ Herrera, Carla, Cynthia L. Sipe, and Wendy S. McClanahan. "Mentoring school-age children: Relationship development in community-based and school-based programs." (2000).

${ }^{25}$ DuBois, David L., Nelson Portillo, Jean E. Rhodes, Naida Silverthorn, and Jeffrey C. Valentine. "How effective are mentoring programs for youth? A systematic assessment of the evidence." Psychological Science in the Public Interest 12, no. 2 (2011): 57-91.

${ }^{26}$ Raposa, Elizabeth B., Jean E. Rhodes, and Carla Herrera. "The impact of youth risk on mentoring relationship quality: Do mentor characteristics matter?." American Journal of Community Psychology 57, no. 3-4 (2016): 320329.

${ }^{27}$ Moreno, Megan A., and Jennifer M. Whitehill. "Influence of social media on alcohol use in adolescents and young adults." Alcohol research: current reviews 36, no. 1 (2014): 91.
} 
the mentee meets an appropriate mentor ${ }^{28}$. In some cases, children and youth members might be at a greater risk of suicidal inclination, substance use, bullying, subject to sexual, physical, or abuse of any kind, requiring instantaneous help. Thus, the flexible approach is indispensable to be incorporated within these programs, where program staff reviews each application thoroughly to scrutinize risk factors associated with it to cater to such individuals on a priority basis.

Collaborative research of two case studies was conducted in the Dublin Institute of Technology that highlighted the benefits of the peer mentoring model, designed for staff-staff and studentstudent mentoring relationships. For instance, in the first case study of staff-staff mentoring, a candidate who participated in the program as a mentor stated significant professional advancement due to mentoring and building relationships with her colleagues within the institute. Likewise, the mentee involved in the peer mentoring found her common ground with the mentor and witnessed psychosocial support, which enriched her confidence, personal, and professional development simultaneously. In the second case study of student-student mentoring, based on several objectives, it was reported by mentees that connecting with a young person at the same academic level was a very supportive experience. The structured and funded social events included in the mentoring program enthused students to get to know their mentors in an informal setting ${ }^{29}$.

\section{METHODOLOGY}

This study used a qualitative approach to investigate the research problem, as it gathered primary data via conducting interviews with the participating individuals. The targeted population for the present study included individuals from different ethnic and religious communities living in various vicinities of Karachi. Using snowball sampling technique, a non-probability sampling technique in which samples have traits that are rare to find, different communities including Bohri, Ismaili, Memon, Parsi, Christian, and Hindu were approached to conduct interviews. From each of the communities, 2 individuals were approached to conduct interviews. From this perspective, interviews could be conducted from 12 individuals altogether. Some of the interviews were conducted online (using online mediums such as Zoom and Google Meet) because of the unavailability of the participants for a physical meeting. All interviews were audio-recorded with the consent of the participants; virtual interviews were recorded via Zoom software while in-person interviews were recorded on mobile devices.

A semi-structured interview guide having open-ended questions was designed to review the availability of community-based mentoring programs in Karachi and assess the knowledge, awareness, and perceptions of different communities about mentoring programs. Each of the interviews lasted around 20 minutes, as various probes were used that were found necessary. The interview guide was designed to discover the disposal of community-based mentoring programs in different communities, to identify and cope with children and youth facing low self-esteem,

\footnotetext{
${ }^{28}$ DuBois, David L., Nelson Portillo, Jean E. Rhodes, Naida Silverthorn, and Jeffrey C. Valentine. "How effective are mentoring programs for youth? A systematic assessment of the evidence." Psychological Science in the Public Interest 12, no. 2 (2011): 57-91.

${ }^{29}$ McCann, Sinéad, and John Delap. "Mentoring Case Studies in the Access and Civic Engagement Office, Dublin Institute of Technology." International Journal of Evidence Based Coaching and Mentoring 13, no. 1 (2015): 106-120.
} 
inadequate decision-making skills, poor career choices, and to find out how these communities support children and youth in their social, emotional, and professional development.

The data gathering instrument (Interview Guide) was divided split into two categories. The first category of the instrument was designed for the participants who followed the community-based programs. The purpose of this instrument category was to examine the types of mentoring programs, selection criteria of mentors, matching criteria, and activities regarding the program offered by the respective community. The second category, on the other hand, of the instrument was designed for the participants who did not follow the community-based programs. They were not aware of the mentoring programs offered by their community. The purpose of this instrument category was to explore their perception regarding the community involvement in building selfesteem and identifying the strategies used by the respective community to recognize low selfesteem, inept decision-making skills, or career choice process among children and youth.

Both categories of the instrument were sent to the respective field experts (holding PhD in the respective discipline) to measure the instrument validity. The rejected questions by the experts in the instrument were removed. After that, a pilot study was conducted to further validate the instrument. In the pilot study, two participants were approached to conduct interviews. The received data was made part of the raw data after revising the instrument accordingly. Initially, the received data was considered as raw data that was transcribed verbatim into the English language, as most of the interviews were conducted in the native language (Urdu language). The transcribed data was then assigned with various coding based on the chosen variables including self-awareness, difficulties encountered in academics, hurdles encountered in career choices, dearth of guidance, contentment and successful positive feeling. The coded transcriptions were given various categories to extract themes for analysis.

\section{RESULTS \& FINDINGS}

\section{Descriptive Analysis}

Questions related to difficulties encountered in educational and professional development and how they could be more successful were answered accurately and objectively by each of the participants. Sixty-seven per cent of the respondents agreed to choose their educational path themselves, while fourteen per cent admitted informal parental guidance, and nine per cent had financial constraints. Eighty-six per cent of the participants admitted liking what they study, while nine per cent were not sure. Sixty per cent of the participant chose their career paths themselves; nine per cent had informal parental guidance, circumstances forced eighteen per cent, and nine per cent had other reasons. Lastly, seventy-five per cent of respondents favoured more helpful guidance (mentorship) in educational fields, and sixty-eight per cent approved more effective direction (mentorship) for better career choices. The majority of the youth chose their educational and professional paths themselves; eighty-six per cent reported to like what they study and ninety-eight per cent like their jobs. Yet, they are not fully satisfied with these choices and desire to be guided better by a more knowledgeable and experienced person (mentor). 


\section{Thematic Analysis}

The purpose of the instrument revolved around three key areas (a) to analyse the availability of community-based mentoring programs among different communities of Karachi, (b) to assess the knowledge, awareness, and perception of these communities about mentoring programs, and (c) to explore how the respective communities support children and youth in their socio-emotional and professional development. Results from the interviews conducted from Bohri, Ismaili, Memon, Parsi, Christian, and Hindu communities indicated that none of the community practice mentoring programs of any kind. The majority of the communities were found ignorant of the mentoring programs, their purposes, and their long-term benefits. However, the key area of the instrument was responded to in great length and precision by all communities. For instance, the dominant focus of the Bohri and Memon communities was found mainly on financial support for the establishment of small-scale and large-scale businesses for their youth. One respondent of the Memon community reported support provided to the youth through university visits and encouraging them to opt for diverse career varieties.

Similarly, the Hindu and Parsi communities reported financial support for higher education furnished to the youth. Parsi community, on the other hand, was found to be providing financial support in the form of loans that students returned after completing the course. Ismaili community outlined several activities performed through the religious education system that assist children and youth cultivate social skills, confidence, and suitable career path through professional guidance and counselling. The Christian community revealed no financial or moral support supplied to their youth.

\section{Discussion}

This research was to investigate the existence of community-based mentoring programs for children and youth in Karachi among various communities and to identify the breaches in prevailing mentoring programs or any other programs served by the districts. Hence it is an unfortunate realization that neither literature research nor our findings propose the presence of mentoring programs among the communities of Karachi. Despite the fact, our nation's youth choose their educational and professional pathways themselves and further report to be content with these choices. Yet, they wish they had some competent figure in their lives that had guided them better and helped them to make versed decisions; hence these findings symbolize the need for mentorship programs in our country, particularly in this century. Thus, the literature review of this paper aimed to instate significant knowledge regarding the mentoring program, model types, forms, and benefits of community-based mentoring programs on children and youth from various strands such as at-risk, substance use, academics, socio-emotional, and professional development of adolescents.

When an older, more knowledgeable and experienced adult associates in a child's life, mainly through an adolescent stage, it helps inculcate self-awareness, skills, and confidence necessary to preclude substance use ${ }^{30}$. Similarly, eminent relationships with compassionate adults tend to

\footnotetext{
${ }^{30}$ LoSciuto, Leonard, Amy K. Rajala, Tara N. Townsend, and Andrea S. Taylor. "An outcome evaluation of Across Ages: An intergenerational mentoring approach to drug prevention." Journal of Adolescent Research 11, no. 1 (1996): 116-129.
} 
yield a wide range of long-term developmental benefits for children and youth ${ }^{31}$. In the light of the present findings, the following features of the current study are worth mentioning. (1) We found no evidence of formal or informal mentoring programs, (2) the majority of the members of the communities do not possess information about the mentoring program, and (3) we received no confirmation of the testimonials of the practices mentioned by two to three communities which could be beneficial for further research.

\section{CONCLUSION \& RECOMMENDATIONS}

This study concludes on the objectives of the study, which constitute of the following: (a) to analyse the availability of community-based mentoring programs among communities, (b) to assess the knowledge, awareness, and perception of different communities about mentoring programs; and (c) to identify the concerns and berries children and youth face in social, emotional and professional development. Thus, we extend our current review on the analysis of the data acquired from this research project that there is a severe lack of recognition and lack of community-based mentoring programs among the targeted communities of Karachi. The study results further signify that children and young adults are not truly satisfied with their careers or educational choices due to many external and internal factors and intensely desire guidance in their education and career options from a more skilled and competent person. Consequently, the absence of the community-based mentoring program betokens the city's need to introduce a wellorganized and formal mentoring program.

The qualitative results unquestionably indicate that a well-organized community-based mentoring program needs to be introduced that can lessen or prevent the challenges encountered by adolescents in their educational and professional paths. Thus, as a contribution, a profound community-based mentoring program is recommended. The mentoring program should be designed with a framework of conceptualized elements such as vision, structure and goals that is intended for youth to provide a guided path for a successful future. The program should offer a mentorship in different areas such as academics, entry-level professional success, adolescents experiencing abuse or substance use of any kind, and skills development for career growth. Furthermore, the program must envision providing mentorship inclusively to all communities and cultivating an attitude of independence in nation's youth. For this reason, mentors to be recruited through strict screening, observation, and reference tests.

${ }^{31}$ Sipe, Cynthia L. "Mentoring: A Synthesis of P/PV's Research: 1988-1995." (1996). 


\section{REFERENCES}

Axford, Nick, Gretchen Bjornstad, Justin Matthews, Laura Whybra, Vashti Berry, Obioha C. Ukoumunne, Tim Hobbs et al. "The effectiveness of a community-based mentoring program for children aged 5-11 years: Results from a randomized controlled trial." Prevention Science 22, no. 1 (2021): 100-112.

Baumeister, Roy F., Jennifer D. Campbell, Joachim I. Krueger, and Kathleen D. Vohs. "Does high self-esteem cause better performance, interpersonal success, happiness, or healthier lifestyles?." Psychological science in the public interest 4, no. 1 (2003): 1-44.

Beiswinger, George L. One to one: The story of the Big Brothers/Big Sisters movement in America. Philadelphia: Big Brothers/Big Sisters of America, 1985.

Bridgeland, John M., and Laura A. Moore. "Untapped Potential: Fulfilling the Promise of Big Brothers Big Sisters and the Bigs and Littles They Represent." Civic Enterprises (2010).

DuBois, David L., and Thomas E. Keller. "Investigation of the integration of supports for youth thriving into a community-based mentoring program." Child Development 88, no. 5 (2017): 1480-1491.

DuBois, David L., Nelson Portillo, Jean E. Rhodes, Naida Silverthorn, and Jeffrey C. Valentine. "How effective are mentoring programs for youth? A systematic assessment of the evidence." Psychological Science in the Public Interest 12, no. 2 (2011): 57-91.

Eccles, Jacquelynne S. "The development of children ages 6 to 14." The future of children (1999): 30-44.

Fanaj, Naim, and Erika Melonashi. "A systematic literature review on self-esteem and psychological well-being in Kosovo." In Human and Social Sciences at the Common Conference, pp. 103-108. 2014.

Feldman, S. Shirley, Glen R. Elliott, and Glen R. Elliott, eds. At the threshold: The developing adolescent. Harvard University Press, 1990.

Flanagan, Laura Melano. "The theory of self psychology." Inside out and outside in: Psychodynamic clinical theory and psychopathology in contemporary multicultural contexts 4 (2011): 158-185.

Guillen, Lorena, and Ken Zeichner. "A university-community partnership in teacher education from the perspectives of community-based teacher educators." Journal of Teacher Education 69, no. 2 (2018): 140-153.

Herrera, Carla, Cynthia L. Sipe, and Wendy S. McClanahan. "Mentoring school-age children: Relationship development in community-based and school-based programs." (2000).

Heywood, Jean S. Children in care: the development of the service for the deprived child. Routledge, 2013. 
Holland III, Melvin A. "Youth Mentoring Through Otherfathering: A Case Study Exploring Adolescent African American Males' Mentor-Mentee Relationship Experiences with African American Men Acting as Otherfathers in an Urban Community-Based Mentoring Setting." PhD diss., Northeastern University, 2019.

Johnson, Amy W., and Judith A. Sullivan. "Mentoring program practices and effectiveness." New Directions for Adult and Continuing Education 1995, no. 66 (1995): 43-56.

King, Keith A., Rebecca A. Vidourek, Beth Davis, and Warren McClellan. "Increasing self-esteem and school connectedness through a multidimensional mentoring program." Journal of school health 72, no. 7 (2002): 294-299.

Li, Jiwen, Mingyan Liu, Maoying Peng, Ke Jiang, Hong Chen, and Juan Yang. "Positive representation of relational self-esteem versus personal self-esteem in Chinese with interdependent self-construal." Neuropsychologia 134 (2019): 107195.

LoSciuto, Leonard, Amy K. Rajala, Tara N. Townsend, and Andrea S. Taylor. "An outcome evaluation of Across Ages: An intergenerational mentoring approach to drug prevention." Journal of Adolescent Research 11, no. 1 (1996): 116-129.

McCann, Sinéad, and John Delap. "Mentoring Case Studies in the Access and Civic Engagement Office, Dublin Institute of Technology." International Journal of Evidence Based Coaching and Mentoring 13, no. 1 (2015): 106-120.

McLeod, Saul. "Maslow's hierarchy of needs." Simply psychology 1, no. 1-18 (2007).

Moreno, Megan A., and Jennifer M. Whitehill. "Influence of social media on alcohol use in adolescents and young adults." Alcohol research: current reviews 36, no. 1 (2014): 91.

Pahwa, Rohini, Melissa E. Smith, Erin L. Kelly, Ryan J. Dougherty, Helle Thorning, John S. Brekke, and Alison Hamilton. "Definitions of community for individuals with serious mental illnesses: Implications for community integration and recovery." Administration and Policy in Mental Health and Mental Health Services Research 48 (2021): 143-154.

Raposa, Elizabeth B., Jean E. Rhodes, and Carla Herrera. "The impact of youth risk on mentoring relationship quality: Do mentor characteristics matter?." American Journal of Community Psychology 57, no. 3-4 (2016): 320-329.

Ruiz-Casares, Mónica, Lauren Kolyn, Richard Sullivan, and Cécile Rousseau. "Parenting adolescents from ethno-cultural backgrounds: A scan of community-based programs in Canada for the promotion of adolescent mental health." Children and Youth Services Review 53 (2015): 10-16.

Sipe, Cynthia L. "Mentoring: A Synthesis of P/PV's Research: 1988-1995." (1996).

Summit Learning, "Power Of Mentorship: Why Every Student (And Teacher) Benefits", Summit Learning Blog, Last modified 2019, https://blog.summitlearning.org/2019/01/mentorshipbenefits/. 